\title{
A qualidade da democracia paraguaia: entre debilidades persistentes e avanços truncados
}

\author{
LILIANA Rocío DUARTE RECALDE \\ Doutoranda em Ciência Política (Universidad Nacional de San Martín, Argentina) \\ Pesquisadora na Universidad Católica "Nuestra Señora de la Asunción" \\ Assunção, Paraguai \\ rociohk@yahoo.com
}

O presente trabalho revisa a situação atual da qualidade da democracia paraguaia, analisando a maneira em que as diferentes dimensões procedimentais, substantivas e de resultado têm se fortalecido ou estagnado desde a abertura do regime em 1989. Desta maneira, identificamos que a prestação de contas eleitoral e institucional instaurada desde o processo de transição são as dimensões que registraram avanços mais claros em termos de qualidade, enquanto a dimensão substantiva correspondente à igualdade e a dimensão de resultados apresentam grandes debilidades, criando as bases para o questionamento da vigência do regime no país.

Palavras-chave: Paraguai; qualidade da democracia; partidos políticos; capacidade de resposta do Estado; legitimidade.

\section{Introdução}

DEMOCRACIA PARAGUAIA enfrentou múltiplos desafios para
sua consolidação desde o final do regime autoritário de Alfredo
Stroessner (1954-1989). A abertura para a democracia, acontecida após a
derrubada da ditadura stronista como consequência do golpe militar de
fevereiro de 1989, implicou a chegada de um período de desconhecidas
liberdades para o exercício da cidadania política no Paraguai, apoiadas em
reformas institucionais que apontaram a reger a convivência democrática
no país. Contudo, no quarto de século decorrido desde essa abertura
mantiveram-se vigentes práticas políticas herdadas da ditadura ligadas ao
manejo arbitrário do poder e à persistência de uma cultura autoritária
entre a população nacional, que chegou a apoiar tendências ditatoriais
no exercício do poder político. A importância de revisar a qualidade
da democracia do Paraguai se evidencia nessa disjuntiva de avanços de-
mocráticos e persistências autoritárias, que se manifestam em diferentes
dimensões do regime.
Tendo como antecedentes os trabalhos sobre a qualidade da demo-
cracia paraguaia de Barreda e Bou (2010) e de Abente Brun (2012), este
artigo pretende avançar nesta linha mediante a apresentação de funda-
mentos empíricos para a análise do caso paraguaio no período entre 1989
e 2014 , a partir das dimensões da qualidade da democracia propostas por
Morlino (2011). Para isso, serão revisadas as qualidades procedimentais da
democracia paraguaia, levando em conta as dimensões de competição e
participação políticas, o império da lei, bem como a prestação de contas
eleitoral e interinstitucional, e depois, as dimensões correspondentes aos 
conteúdos e resultados da democracia, em que serão levadas em conta a liberdade e igualdade produzidas, além da capacidade de resposta da democracia paraguaia. Finalmente, será feita uma avaliação global sobre as fraquezas persistentes nas dimensões analisadas e os desafios à consolidação de uma democracia de qualidade no Paraguai.

\section{Qualidades procedimentais}

\subsection{Prestação de contas eleitoral}

A prestação de contas eleitoral se apresenta como a dimensão de maior estabilidade na democracia paraguaia e permite reconhecer a presença das condições mínimas da poliarquia indicadas por Dahl (1971) no sistema político do país. Esta dimensão deriva sua fortaleza da regularidade e da previsibilidade na realização de eleições municipais desde 1991 e de eleições gerais desde 1993, bem como da falta de contestação social dos resultados obtidos nas urnas desde a abertura à democracia em 1989. A Constituição de 1992 estabeleceu as bases legais para a celebração de eleições democráticas e para a substituição regular de chefes de Estado sem possibilidade de reeleição, se bem que a alternância partidária à frente do Poder Executivo aconteceu só em 2008, quando a eleição de Fernando Lugo pela Aliança Patriótica para a Mudança $(\mathrm{APC})^{1}$ pôs fim ao controle contínuo da Presidência da República que a Associação Nacional Republicana (ANR ou Partido Colorado) mantinha havia 61 anos.

Desde 1995, o Tribunal Superior de Justiça Eleitoral (TSJE) é o responsável pela organização e realização das eleições, pela direção e fiscalização do registro eleitoral e pela administração dos recursos atribuídos no Orçamento Geral da Nação para fins eleitorais. Este organismo tem entre suas atribuições o controle e a fiscalização patrimonial dos partidos, movimentos políticos e alianças eleitorais, bem como a distribuição entre eles dos aportes e subsídios do Estado. É o único responsável legal pelas eleições, e contra suas resoluções só cabe ação de inconstitucionalidade. Entretanto, sua capacidade de atuar como árbitro imparcial tem sido questionada devido a que sua estrutura está dominada por representantes dos partidos tradicionais, ao tempo que se mostrou incapaz de aplicar a lei de maneira plena em casos de fraude eleitoral ${ }^{2}$.

Embora exista liberdade para a organização de partidos, o registro de candidatos e a realização de campanhas políticas no país, outros fatores que limitam a qualidade desta dimensão são a escassa diversidade social representada pelos partidos tradicionais e a limitada presença de partidos alternativos representantes dos setores sociais tradicionalmente excluídos (Duarte Recalde, 2013a), que contribuem para debilitar, em última instância, a qualidade do mecanismo de prestação de contas eleitoral.

\subsection{Prestação de contas interinstitucional}

No que respeita à dimensão horizontal da prestação de contas, a balança de poder é favorável ao Legislativo em relação ao Executivo, devido a seu poder para solicitar relatórios, citar e interpelar ministros do Executivo e altos funcionários públicos, emitir votos de censura, sancionar o Orçamento Geral da Nação, entre outras faculdades. O Congresso também pode levar a impeachment o Presidente da República, potestade que foi aproveitada em junho de 2012 em um contexto de irregularidades procedimentais, sem ter apresentado provas na acusação ao então presidente Fernando Lugo, sem lhe dar um período adequado para a elaboração da sua defesa e tornando pública a sentença por antecipado, o que caracterizou arbitrariedade no exercício do poder e implicou a interrupção do processo de consolidação da democracia paraguaia (Duarte Recalde, 2013b).

A administração de justiça no país é competência do Poder Judiciário, que é formalmente independente e tem autonomia orçamentária. Os magistrados usufruem de imunidades para o exercício das suas funções e são inamovíveis durante o período para o qual foram designados, podendo ser removidos só por decisão do Júri de Julgamento de Magistrados. A Corte Suprema de Justiça tem competências claramente delimitadas e não pode anular decisões dos Poderes Executivo e Legislativo, embora sua composição responda a critérios de quoteo partidário que abrem o caminho para o questionamento da sua imparcialidade. Por outra parte, apesar de no Paraguai existir a Defensoria do Povo,

1 A Aliança Patriótica para a Mudança constitui uma coalizão eleitoral de partidos de diversos posicionamentos ideológicos conformada com vistas às eleições gerais de 2008, cuja força eleitoral derivou principalmente das bases do Partido Liberal Radical Autêntico (PLRA).

2 Informe final: elecciones generales 21 de abril de 2013, Missão de Observação Eleitoral da União Europeia (MOE UE), disponível em <http:// www.cej.org.py/files/InformeFinalMOEUEParaguay2013-FINAL.pdf>, acesso em 20 de jun. 2015, e Informe final de la Misión de Observación Electoral de la OEA sobre las elecciones generales y departamentales: presidente y vicepresidente, senadores, diputados, parlamentarios del Mercosur, gobernadores y miembros de juntas departamentales celebradas en Paraguay el 20 de abril de 2008, Organização dos Estados Americanos (OEA), disponível em 
Tabela 1: Participação em eleições gerais - Poder Legislativo

\begin{tabular}{lcccccc}
\hline Ano & $\begin{array}{c}\text { Participação } \\
\text { efetiva }\end{array}$ & $\begin{array}{c}\text { Total de votos } \\
\text { emitidos }\end{array}$ & $\begin{array}{c}\text { Cédula Eleitoral } \\
\text { Nacional }\end{array}$ & $\begin{array}{c}\text { Votos emitidos } \\
\text { / população em } \\
\text { idade de votar }\end{array}$ & $\begin{array}{c}\text { População em } \\
\text { idade de votar }\end{array}$ & População total \\
\hline 2013 & $68,24 \%$ & 2.399 .626 & 3.516 .275 & $58,15 \%$ & 4.126 .948 & 6.623 .252 \\
2008 & $65,48 \%$ & 1.874 .127 & 2.861 .940 & $49,86 \%$ & 3.759 .034 & 6.669 .086 \\
2003 & $64,02 \%$ & 1.539 .800 & 2.405 .108 & $47,47 \%$ & 3.243 .812 & 5.884 .491 \\
1998 & $80,48 \%$ & 1.649 .419 & 2.049 .449 & $59,38 \%$ & 2.777 .725 & 5.137 .440 \\
\hline
\end{tabular}

Fonte: International IDEA, 2015

desde sua inclusão na Constituição de 1992 se passaram nove anos até que o Poder Legislativo designasse como primeiro responsável a ocupar esse cargo Manuel Páez Monges, que se manteve nele seis anos mais do que seu mandato estabelecia e cuja competência foi amplamente questionada por defensores dos direitos humanos no país (Gauto, 2014).

Dado que representantes legislativos participam do Conselho da Magistratura e do Júri de Julgamento de Magistrados, enquanto o Congresso tem a atribuição exclusiva de eleger o Controlador Geral da República, a ingerência do Poder Legislativo sobre o Poder Judicial é direta. Desta maneira, o exercício de controle entre os poderes do Estado fica subordinado a interesses conjunturais dos representantes no governo. Assim, as debilidades no funcionamento do mecanismo de controle interinstitucional deixam a prestação de contas eleitoral como principal instância de controle à gestão dos governantes, de modo que a democracia paraguaia mantém uma característica essencialmente delegativa (O’Donnell, 1994).

\subsection{Participação política}

No que se refere à participação política, observa-se que a participação convencional se encontra institucionalizada na práxis política nacional, com fundamento na universalidade do voto. A participação eleitoral tem se mantido consistentemente acima de $60 \%$ desde que o TSJE supervisiona as eleições (Tabela 1). Se o registro eleitoral é permanente e a inscrição é automática para quem fez 18 anos a partir de 16 de janeiro de 2012, aqueles que fizeram antes ainda devem ir a um local de inscrição e ser cadastrados, o que se constitui em um problema em localidades isoladas onde a presença dos funcionários do TSJE é esporádica, de modo que muitas pessoas não têm a possibilidade de exercer este direito político. O exercício do voto também se vê limitado pela disposição de mesas de votação com difícil acesso, que representaram 20\% do total em $2013^{3}$.

As formas de participação não convencionais são desalentadas, já que os direitos de reunião e manifestação são sistematicamente violados no país, e se registram numerosos casos de protestos reprimidos pela polícia, entre os que se encontram reclamações contra aumentos nos custos de serviços, a defesa do meio ambiente e reivindicações de gênero, sindicais e estudantis (Galeano, 2014). Quanto aos movimentos sociais, as organizações camponesas são as mais numerosas e bem estabelecidas, tendo instituído marchas de protesto nas quais milhares de pessoas se mobilizam em todo o país com reivindicações específicas, além de incorrer na prática de ocupar terras ou de realizar bloqueios de estradas intermitentes. Contudo, os diferentes grupos campesinos tendem a ser criminalizados, e suas manifestações costumam ser recebidas com repressão, tendo sido registradas execuções de dirigentes que ficaram impunes (Benítez e Leguizamón, 2014).

Por outra parte, estima-se que só $32,9 \%$ da população participam em atividades comunitárias e que 11,6\% chegam a exercer papeis de liderança ${ }^{4}$. Assim, a participação política no Paraguai continua se limitando, em grande medida, ao exercício do sufrágio e ao âmbito de ação dos partidos políticos.

\subsection{Competição política}

A qualidade da competição política no Paraguai se mantém débil principalmente devido à ausência de alternativas políticas que reflitam a multiplicidade de interesses sociais e posicionamentos ideológicos presentes entre a população. $\mathrm{O}$ sistema político paraguaio tem se

3 Informe final: elecciones generales 21 de abril de 2013, MOE UE, disponivel em <http://www.cej.org.py/files/ InformeFinalMOEUEParaguay2013-FINAL.pdf>, acesso em 20 de jun. 2015.

4 The political culture of democracy in the Americas, 2012: towards equality of opportunity, United States Agency for International Development (USAID), disponível em <http://www.vanderbilt.edu/lapop/ab2012/AB2012-comparative-Report-V7-Final-Cover -01.25.13.pdf>, acesso em 20 de jun. 2015. 
Tabela 2: Distribuição partidária por câmaras - Paraguai, 2015

\begin{tabular}{lcc}
\hline Partidos & Senadores & Deputados \\
\hline Associação Nacional Republicana (Partido Colorado) & 19 & 44 \\
Partido Liberal Radical Autêntico & 13 & 27 \\
Frente Guasu & 5 & 1 \\
Partido Democrático Progressista & 3 & - \\
Avança País & 2 & 2 \\
União Nacional de Cidadãos Éticos & 2 & 2 \\
Partido Encontro Nacional & 1 & 2 \\
Partido Pátria Querida & - & 1 \\
Paixão Chaquenha & - & 1 \\
\hline
\end{tabular}

Fontes: Câmara dos Senadores e Câmara dos Deputados

caracterizado desde o século XIX por um bipartidarismo protagonizado pelos partidos Colorado e Liberal, os quais mantêm escassa diferenciação ideológica ou programática. Este bipartidarismo ainda se reflete em ambas as câmaras do Poder Legislativo (Tabela 2).

A entrada na competição por cargos eletivos deve estar antecedida por eleições internas nos partidos e alianças que pretendem pugnar por cargos públicos. As eleições internas celebradas desde a abertura para a democracia no país em 1989 têm estado caracterizadas pelas denúncias de fraude ${ }^{5}$ e de outras práticas eleitorais que não chegaram a ser advertidas.

No que se refere ao financiamento partidário, a atividade eleitoral se encontra subsidiada parcialmente pelo Estado, e está permitido o financiamento privado ilimitado, com a ressalva de que os fundos não podem vir de fora do país, de entidades públicas, associações sindicais, empresas transnacionais ou vinculadas a jogos de azar. O subsídio estatal é destinado aos partidos políticos de acordo com o número de votos obtidos nas últimas eleições parlamentares. Apesar disso, o mesmo subsídio não é outorgado a movimentos ou alianças eleitorais. Não existem limites nem controle dos gastos de campanha. De acordo com o relatório mais recente da Missão de Observação Eleitoral da União Europeia no Paraguai, "as regras sobre financiamento de partidos e da campanha eleitoral não garantiram um regime equilibrado e transparente, o que contradiz os compromissos internacionais e regionais assinados pelo Paraguai" ${ }^{\circ}$.

\subsection{Estado de Direito}

Ao levar em conta a vigência do Estado de Direito no Paraguai, se observa que a maior fortaleza desta dimensão se relaciona com o controle civil que se mantém sobre as forças de segurança. No que se refere à segurança individual e à ordem civil, por sua parte, a taxa de homicídios por cada 100.000 habitantes no Paraguai diminuiu consistentemente nos últimos anos, passando de 24,6 em 2002 a 8,38 em 2014. Essa taxa aumenta em grande medida ao levar em conta o departamento de Amambay, na fronteira com o Brasil, onde as estatísticas revelavam 66,73 casos de homicídios por cada 100.000 habitantes em 2014 ${ }^{7}$. A delinquência organizada está ligada de maneira informal a grupos mafiosos relacionados ao narcotráfico em zonas de fronteira com a Argentina e o Brasil, regiões onde se concentra a maior parte do cultivo de maconha do país. As principais organizações de tráfico de drogas são lideradas por pessoas de origem brasileira, que também têm ligações com o tráfico de armas ${ }^{8}$.

A responsabilidade oficial de garantir o império da lei no país recai sobre o Poder Judiciário, cuja

5 Um caso paradigmático foi a admissão de fraude cometida pelo senador colorado Juan Carlos Galaverna nas eleições internas do Partido Colorado em 1992, que tiveram Juan Carlos Wasmosy como vencedor. A confissão de Galaverna em declarações à imprensa, acontecida em 8 de janeiro de 2008, ficou arquivada e impune.

6 Informe final: elecciones generales 21 de abril de 2013, MOE UE, p. 22, disponível em <http://www.cej.org.py/files/InformeFinalMOEUEParaguay2013-FINAL.pdf>, acesso em 20 de jun. 2015.

7 Análisis estadístico: Homicidio doloso en el Paraguay 2010-2015, Ministério do Interior (MDI), disponível em <http://www.mdi.gov.py/images/Observatorio_files/Denuncias\%20y\%20v\%C3\%ADctimas\%20de\%20Homicidio\%20Doloso\%202010-2015. pdf>, acesso em 20 de jun. 2015.

8 International narcotics control strategy report, 2008, Departamento de Estado dos Estados Unidos, disponível em <http://www.state.gov/documents/organization/102583.pdf>, acesso em 20 de jun. 2015. 
Tabela 3: Evolução da população penal no Paraguai (por 100.000 habitantes)

\begin{tabular}{ccccccc}
\hline & $\mathbf{1 9 9 8}$ & $\mathbf{2 0 0 8}$ & $\mathbf{2 0 0 9}$ & $\mathbf{2 0 1 2}$ & $\mathbf{2 0 1 3}$ & $\mathbf{2 0 1 4}$ \\
\hline Taxa & 74,7 & 96,3 & 99,5 & 116,1 & 136,5 & 157,7 \\
\hline
\end{tabular}

Fonte: MARTENS, 2014, p. 392

independência política é questionada regularmente ${ }^{9} \mathrm{e}$ gera limitada confiança entre a população. Segundo o Latinobarómetro $^{10}, 20,7 \%$ dos paraguaios inqueridos manifestam ter algo de confiança no Poder Judiciário, frente a $38,6 \%$ que manifestam ter pouca confiança e $34,6 \%$ que indicam não ter nenhuma confiança. Embora este poder tenha independência institucional, a falta de independência em relação aos partidos incide negativamente na qualidade desta dimensão.

Por outra parte, as capacidades institucionais e administrativas do Estado estão condicionadas por um funcionamento historicamente clientelista, já que as nomeações e as definições salariais dos funcionários responderam tradicionalmente a interesses partidários ou pessoais em lugar de guiar-se por critérios meritocráticos (Schuster, 2013). Os funcionários públicos se encontram em situação de imprevisibilidade no trabalho devido a que não está implementada uma política regular de promoção do pessoal nem são garantidos salários de acordo com o mínimo estabelecido legalmente ${ }^{11}$, situação que facilita sua predisposição a incorrer em práticas de corrupção. A corrupção do Estado, definida como o "preço da paz" durante os anos de ditadura stronista (Schuster, 2013, p. 7), também permanece como uma das principais limitações à qualidade do império da lei. O Paraguai se mantém entre os países mais corruptos do continente americano, segundo a Transparência Internacional, tendo uma situação melhor em 2014 só do que as de Haiti e Venezuela e ocupando a $150^{a}$ posição no mundo. Em conformidade com a situação descrita, existe percepção de que a corrupção na função pública está generalizada ${ }^{12}$ no Paraguai e de que não há indícios de luta eficaz contra ela.

\section{Qualidades de conteúdo}

\subsection{Liberdade}

Ao analisar a qualidade da democracia desde a perspectiva do respeito às liberdades individuais, percebe-se que os direitos políticos são os mais respeitados no país, enquanto se apresentam falências no respeito à dignidade pessoal e aos direitos civis, apesar das salvaguardas legais. Observa-se a violação sistemática de direitos de certos grupos sociais, como são as comunidades indígenas, camponeses sem terra, comunidades rurais próximas a plantações de soja ou pessoas em situação de extrema pobreza (CODEHUPY, 2009, p. 44). Desta maneira, os níveis de proteção ou segurança garantidos desde o Estado variam segundo o lugar de residência, o estrato socioeconômico ao que se pertence, a profissão, a preferência sexual ou o gênero da pessoa.

Mesmo que se estabeleça constitucionalmente que ninguém pode ser detido sem ordem escrita senão em flagrante delito, efetivos da Polícia Nacional "praticam detenções ilegais e arbitrárias com fins extorsivos e/ ou para justificar procedimentos ou casos em que não podem identificar ou deter os responsáveis dos fatos investigados" (Martens, 2014, p. 397). A detenção prolongada ou sem juízo ${ }^{13}$ de pessoas é um grave flagelo do sistema penal do país. Embora a prisão preventiva deva ser revogada quando sua duração superar ou for equivalente ao mínimo da pena prevista, não existe vigilância do Estado para o cumprimento desta norma. Ademais, as prisões do país não têm registro informático da entrada de detentos, constando motivos e datas em que indefectivelmente deverão recuperar sua liberdade. São registrados também casos de delinquentes juvenis que cumpriram suas penas em penitenciárias de adultos (USAID, 2009). Estas situações resultam em condições de superlotação entre a população penitenciária, que tem aumentado consistentemente (Tabela 3).

9 Dura crítica al Poder Judicial en congreso, ABC Color, 8 de jul. 2013, disponível em<http://www.abc.com.py/edicion-impresa/suplementos/ judicial/dura-critica-al-poder-judicial-en-congreso-592799.html>, acesso em 20 de jun. 2015.

10<?> Índice Integrado 1995-2013, Latinobarómetro, disponível em <http://www.latinobarometro.org/latOnline.jsp>, acesso em 20 de jul. 2015. 11 11,3\% dos assalariados não chegam a receber o salário mínimo vigente de Gs. 1.824 .055 (US\$364, pela taxa de câmbio de abril de 2015), segundo a Enquete Permanente de Lares relativa a 2013, da Direção Geral de Estatísticas, Enquetes e Censos (DGEEC), Paraguai. No que respeita ao setor privado, esta proporção chega a 50,9\%.

12 De acordo com informe de 2011 do Latinobarómetro, 60\% dos paraguaios inquiridos consideram que a corrupção é um déficit da democracia. $13 \mathrm{Em} 2009$ foram libertadas pessoas que estavam presas ilegalmente por até 11 anos e outras que estavam presas mesmo sem contar com a ordem de um juiz competente. 
Estão constitucionalmente proscritas a escravidão, as servidões pessoais e o tráfico de seres humanos, ao tempo que existiram avanços nos âmbitos administrativo e judicial para zelar por seu cumprimento. Porém, continuam sendo registrados casos de condições análogas à escravidão e tráfico de pessoas, especialmente entre menores de idade de escassos recursos e provenientes de comunidades indígenas (Bachero, Leguizamón e Fernández, 2014). O delito de tráfico de mulheres indígenas jovens é cometido usualmente por capatazes "que aproveitam seu poder frente à necessidade de outorgar/manter fontes de emprego de mulheres que necessitam trabalhar ou das irmãs dos jovens trabalhadores" (Caputo, 2012, p. 357). O Estado paraguaio não conta com mecanismos de proteção adequados para pessoas ou grupos que costumam sofrer discriminações, e é reconhecida a existência de casos de discriminação por parte das forças da ordem pública com travestis, trabalhadoras sexuais, pessoas de escassos recursos, bem como dirigentes sociais, que são sujeitos a detenções ilegais e arbitrárias em todo o país (Martens e Orrego, 2009, p. 131).

O Paraguai mantém status de país parcialmente livre para a Freedom House desde $2004^{14}$. Embora haja grande variedade de meios de imprensa escrita, redes comerciais de televisão e emissoras de rádio, a propriedade dos meios de comunicação está concentrada em sete grandes conglomerados empresariais. Mesmo não existindo casos de censura por parte do Estado nem mecanismos formais de censura nos meios privados, os jornalistas não têm a possibilidade de fato de exercer plenamente sua liberdade de expressão, pois são pressionados informalmente para não refletir posturas que vão contra os interesses de seus empregadores, partidos políticos ou autoridades estatais ${ }^{15}$.

\subsection{Igualdade}

A qualidade da igualdade resultante da experiência democrática paraguaia é um de seus pontos mais fracos, dada a exígua destinação à população de recursos econômicos, culturais e sociais que se contrapõem ao reconhecimento formal de tais direitos. A qualidade da igualdade também resulta afetada pela perpetuação da discriminação estrutural que afeta a importantes setores da população.

No que respeita aos direitos econômicos, a pobreza e a desigualdade são graves flagelos que afligem a população paraguaia. Os indicadores de pobreza não se desenvolveram de acordo com uma tendência específica ao longo da última década e meia (Tabela 4), apesar disso, observa-se que a pobreza rural supera à da área urbana consistentemente. $\mathrm{O}$ mesmo acontece ao se levar em conta os níveis de desigualdade que existem entre a população (Tabela 5), já que se observa que a desigualdade na área rural supera constantemente à da área urbana.

Esses índices mantêm relação com a posse desigual de recursos de produção, que se concentram principalmente em mãos privadas, particularmente no que respeita à posse da terra, que é o principal fator que dá origem à conflitualidade social que afeta o Paraguai. De acordo com dados do censo agropecuário de 2008, $2,6 \%$ dos proprietários no país concentram $85,5 \%$ das terras (Palau, 2009), das quais mais de 7 milhões de hectares se constituem em terras obtidas por meios ilícitos, ou seja, aquelas terras fiscais que foram cedidas durante o governo stronista - e os sucessivos governos da ANR de maneira irregular ${ }^{16}$. A presença estrangeira se impõe neste sentido, já que grandes extensões de terra se encontram em propriedade dos chamados "brasiguaios", que exploram o setor das oleaginosas, especialmente a soja, enquanto a produção leiteira e pecuária está, em geral, em mãos de colonos alemães ou japoneses (Fogel, 2009).A expansão da fronteira da produção de soja promoveu um deslocamento de população do campo a zonas urbanas marginais do Departamento Central e de Assunção, onde se desenvolveram os principais cinturões de pobreza.

No que se refere à existência de discriminações, de acordo com relatório do Latinobarómetro17, apenas $29 \%$ dos paraguaios consideram que existe discriminação por raça, abaixo da média de $36 \%$ da região.

\footnotetext{
14 Freedom House, disponível em <http://www.freedomhouse.org/sites/default/files/FIW\%202013\%20Booklet\%20-\%20for\%20Web_0.pdf>, acesso em 20 de jun. 2015.

15 Informe final: elecciones generales 21 de abril de 2013, MOE UE, disponível em <http://www.cej.org.py/files/ InformeFinalMOEUEParaguay2013-FINAL.pdf>, acesso em 20 de jun. 2015.

16 O tomo IV do relatório final da Comissão da Verdade e Justiça, Paraguai, contém a lista daqueles que receberam terras que não podiam ser beneficiários da reforma agrária, cujo sujeito era "a população camponesa que não possui terras ou a tem de forma insuficiente" (CVJ, 2008:15). Muitos deles, "presidentes da República, ministros do Poder Executivo, altos funcionários de governo, militares e policiais em serviço ativo, senadores e deputados, políticos, latifundiários, bem como empresários e industriais não dedicados à agricultura nem à pecuária e que não residem nos lotes e até ditadores perseguidos pela justiça de seu país e refugiados pela ditadura paraguaia no Paraguai" (CVJ, 2008:207), continuam ativos na vida política nacional.
}

17 Informe 2011, Latinobarómetro, disponível em <http://www.latinobarometro.org/latino/LATContenidos.jsp>, acesso em 20 de jun. 2015. 
Tabela 4: Evolução da pobreza, 1997-2014 (\%)

\begin{tabular}{lllllllllllllllllll}
\hline & 1997 & 1999 & 2000 & 2002 & 2003 & 2004 & $\mathbf{2 0 0 5}$ & $\mathbf{2 0 0 6}$ & $\mathbf{2 0 0 7}$ & $\mathbf{2 0 0 8}$ & $\mathbf{2 0 0 9}$ & $\mathbf{2 0 1 0}$ & $\mathbf{2 0 1 1}$ & $\mathbf{2 0 1 2}$ & $\mathbf{2 0 1 3}$ & $\mathbf{2 0 1 4}$ \\
\hline $\begin{array}{l}\text { Total } \\
\text { País }\end{array}$ & 51,6 & 52,6 & 52,1 & 62,7 & 52,5 & 48,9 & 44,2 & 55,3 & 51,8 & 37,9 & 35,1 & 34,7 & 32,4 & 26,9 & 23,8 & 22,6 \\
$\begin{array}{l}\text { Área } \\
\text { urbana }\end{array}$ & 36,1 & 37,3 & 36,8 & 49,7 & 44,0 & 41,3 & 38,6 & 43,7 & 41,2 & 30,2 & 24,7 & 24,7 & 23,9 & 16,5 & 17,0 & 16,2 \\
$\begin{array}{l}\text { Área } \\
\text { rural }\end{array}$ & 22,5 & 24,0 & 23,7 & 39,7 & 37,4 & 35,5 & 34,4 & 35,3 & 33,6 & 48,8 & 49,8 & 48,9 & 44,8 & 42,1 & 33,8 & 32,0 \\
\hline
\end{tabular}

Fonte: DGEEC, 2014

Tabela 5: Índice de Gini, 2001-2014

\begin{tabular}{lcccccccccccccc}
\hline & $\mathbf{2 0 0 0 - 1}$ & $\mathbf{2 0 0 2}$ & $\mathbf{2 0 0 3}$ & $\mathbf{2 0 0 4}$ & $\mathbf{2 0 0 5}$ & $\mathbf{2 0 0 6}$ & $\mathbf{2 0 0 7}$ & $\mathbf{2 0 0 8}$ & $\mathbf{2 0 0 9}$ & $\mathbf{2 0 1 0}$ & $\mathbf{2 0 1 1}$ & $\mathbf{2 0 1 2}$ & $\mathbf{2 0 1 3}$ & $\mathbf{2 0 1 4}$ \\
\hline $\begin{array}{l}\text { Total } \\
\text { País }\end{array}$ & 0.538 & 0.533 & 0.546 & 0.520 & 0.510 & 0.522 & 0.525 & 0.506 & 0.487 & 0.512 & 0.520 & 0.476 & 0.478 & 0.510 \\
$\begin{array}{l}\text { Área } \\
\text { urbana } \\
\begin{array}{l}\text { Área } \\
\text { rural }\end{array}\end{array}$ & 0.496 & 0.480 & 0.515 & 0.487 & 0.496 & 0.495 & 0.472 & 0.453 & 0.423 & 0.459 & 0.470 & 0.415 & 0.448 & 0.460 \\
\hline
\end{tabular}

Fonte: DGEEC, 2014

Contudo, apesar de o guarani ser o idioma predominante em $59 \%$ dos lares ${ }^{18}$, há generalizada discriminação linguística com os falantes nativos desse idioma. Programas educacionais e documentos oficiais são redigidos, em geral, só em espanhol, a informação transmitida pelos meios de comunicação comercial está, principalmente, em espanhol, e falar guarani em lugar do espanhol chega a funcionar como fator de exclusão, já que implica não ter acesso à educação superior ou a bons empregos.

A discriminação de gênero está muito presente em todos os âmbitos da vida social, refletida no Índice de Desigualdade de Gênero de 0.457 para o Paraguai, segundo o Programa das Nações Unidas para o Desenvolvimento $(\mathrm{PNUD})^{19}$. A presença de mulheres nas instâncias representativas é limitada. Como resultado das últimas eleições gerais, as mulheres se limitam a 20\% da composição do Senado, 15\% da Câmara dos Deputados,
$6 \%$ da titularidade dos governos departamentais, 16\% da representação paraguaia no PARLASUR e 16,22\% da composição das juntas departamentais ${ }^{20}$. A participação das mulheres no mercado de trabalho é de $55,4 \%$, em comparação a $84,8 \%$ dos homens, de acordo com os dados já citados do PNUD; a brecha de renda por hora de trabalho entre homens e mulheres chega a $7 \%$; e considera-se que o Paraguai é um dos países onde as mulheres enfrentam as maiores barreiras para aceder a altas posições no trabalho ${ }^{21}$. Só $36,82 \%$ da população feminina adulta atingem um nível de educação secundária ou superior, em comparação a 40,84\% dos homens, segundo o PNUD de novo. O predomínio de pautas culturais machistas se reflete na sempre presente violência perpetrada contra as mulheres, seja sexual, fisica, econômica ou psicológica.

A precariedade na qualidade da cidadania, acentuada pela desigualdade, se apoia também na situação do

18 Resultados finales del Censo Nacional de Población y Viviendas, 2013, DGEEC, disponível em <http://www.dgeec.gov.py/Publicaciones/Biblioteca/Web\%20Paraguay\%20Total\%20Pais/1\%20Presentacion20Total.pdf>, acesso em 20 de jun. 2015.

19 Paraguay: Human Development Indicators, PNUD, disponível em <http://hdr.undp.org/en/countries/profiles/PRY>, acesso em 20 de jul. 2015. 20 Informe final: elecciones generales 21 de abril de 2013, MOE UE, disponível em <http://www.cej.org.py/files/ InformeFinalMOEUEParaguay2013-FINAL.pdf>, acesso em 20 de jun. 2015.

21 Nuevo siglo, viejas disparidades: brechas de ingresos por género y etnicidad en América Latina y el Caribe, Banco Interamericano de Desenvolvimento (BID), disponível em

<http://idbdocs.iadb.org/wsdocs/getdocument.aspx?docnum=37204140>, acesso em 20 de jun. 2015. 
Tabela 6: Principais indicadores de saúde da população por ano, segundo área de residência

\begin{tabular}{lllll}
\hline & $\mathbf{2 0 1 0}$ & $\mathbf{2 0 1 2}$ & $\mathbf{2 0 1 3}$ & $\mathbf{2 0 1 4}$ \\
\hline Acesso total à saúde (\%) & 71,9 & 69,7 & 73,8 & 80,3 \\
Acesso à saúde - área urbana (\%) & 76,1 & 75,4 & 79,6 & 83,1 \\
Acesso à saúde - área rural (\%) & 66,0 & 63,0 & 66,4 & 76,9 \\
\hline
\end{tabular}

Fonte: DGEEC, 2010-2014

trabalho no país. De acordo com o Latinobarómetro ${ }^{22}$, $30 \%$ da população consideram que o problema mais importante no Paraguai é o desemprego. A taxa de desemprego aberto corresponde a $6 \%$ da população nacional, além de $20 \%$ de população subempregada, e só $43 \%$ das pessoas assalariadas estão dentro de um sistema de aposentadoria ${ }^{23}$.

Ao levar em conta o bem-estar social como parâmetro de equidade, observa-se que a proporção do PIB de 2012 destinado à saúde foi de 4,2\%, enquanto 11,6\% da população se encontravam abaixo do nível mínimo de consumo de energia alimentar ${ }^{24}$. $\mathrm{O}$ acesso à saúde na área urbana é superior ao que tem a população rural (Tabela 6), afinal, a qualidade do acesso da população paraguaia a serviços de saúde continua estando subordinado à disponibilidade de pessoal médico, medicamentos e insumos em centros de saúde públicos, que, por sua vez, estão concentrados nas zonas urbanas do país ${ }^{25}$.

Finalmente, o acesso à educação que tem a população paraguaia incide na capacidade que os indivíduos desenvolvem de tomar consciência dos seus direitos e obrigações, necessária para evitar que a condição de cidadania se limite a um discurso jurídico. Observa-se que a população rural apresenta maiores níveis de analfabetismo, menor quantidade de anos de estudo em média e menores índices de frequência escolar que seus pares urbanos (Tabela 7).

O sistema educacional paraguaio continua tendo diversas limitações instrumentais que incidem nos índices de escolarização e deserção escolar, os quais compreendem as inadequadas condições edilícias das instituições, a insuficiência do número de salas de aula e mobiliário para receber o número crescente de estudantes, a ausência de bibliotecas ou recursos informáticos, além da localização pouco acessível dos centros educativos em zonas rurais. Desta maneira, grande parte da população não conta com os recursos simbólicos para o exercício dos seus direitos sociais nem políticos, o que caracteriza uma situação de "democracia sem cidadania efetiva” (Przeworski, 2010, p. 29) no Paraguai.

\section{Qualidade de resultados: capacidade de resposta}

A qualidade dos resultados da democracia no Paraguai resulta afetada pelo fato de que o reconhecimento formal dos direitos dos cidadãos não está acompanhado de políticas públicas para sua implementação ou do investimento de recursos econômicos a fim de solucioná-los. A desatenção do Estado paraguaio às necessidades da população, apoiada em fatores objetivos que limitam a capacidade de resposta em um contexto de democracia, dificulta a realização de mudanças estruturais e determina a baixa qualidade da dimensão em geral.

A quantidade de recursos do Estado disponíveis para implementar as políticas públicas não condiz com as necessidades sociais no país, já que o gasto público social representou $17,9 \%$ do $\mathrm{PIB}$ de 2012 , sendo que $4,2 \%$ corresponderam a saúde, $4,66 \%$ a educação, $7,3 \%$ a seguridade social e $0,5 \%$ a moradia e outros ${ }^{26}$. Ao limitado alcance do Estado paraguaio se soma sua escassa força extrativa em impostos, pois, em 2011, os ingressos tributários representaram só 13,35\% do PIB (Rodríguez, 2012). A qualidade eminentemente regressiva da estrutura impositiva paraguaia, sustentada pelo imposto ao consumo $^{27}$, incide, por sua vez, na persistência da desigualdade econômica entre a população.

22 Informe 2011, Latinobarómetro, disponível em <http://www.latinobarometro.org/latino/LATContenidos.jsp>, acesso em 20 de jun. 2015.

23 Condiciones de vida 2010-2014, DGEEC, disponível em <http://www.dgeec.gov.py/register/bases\%20EPH2014/ Condiciones\%20de\%20 Vida\%20EPH2010-2014.pdf>, acesso em 20 de jun. 2015.

24 Comissão Econômica para a América Latina e o Caribe (CEPAL), disponível em <http://websie.eclac.cl/sisgen/Consultalntegrada.asp>, acesso em 20 de jun. 2015.

25 Estima-se que 70\% das e dos agentes de saúde se encontram na região de Assunção e arredores, onde residem 30\% da população paraguaia. 26 CEPAL, disponível em <http://websie.eclac.cl/sisgen/Consultalntegrada.asp>, acesso em 20 de jun. 2015.

27 A arrecadação impositiva proveniente do Imposto sobre o Valor Agregado (IVA) representou consistentemente mais de 40\% do total arrecadado pelo Estado paraguaio, segundo a Subsecretaria de Estado de Tributação (Duarte Recalde, 2014). 
Tabela 7: Principais indicadores de educação da população por ano, segundo área de residência

\begin{tabular}{|c|c|c|c|c|c|}
\hline & 2010 & 2011 & 2012 & 2013 & 2014 \\
\hline \multicolumn{6}{|l|}{ Total } \\
\hline População analfabeta de 15 anos e mais (\%) & 6,1 & 5,4 & 6,0 & 5,3 & 5,4 \\
\hline Média de anos de estudo - população de 10 anos e mais & 7,7 & 8,1 & 8,1 & 8,4 & 8,5 \\
\hline Assistência escolar - população de 6-9 anos (\%) & 97,1 & 97,3 & 97,8 & 98,5 & 98,1 \\
\hline Assistência escolar - população de 10-14 anos (\%) & 94,7 & 95,8 & 95,6 & 96,5 & 96,4 \\
\hline \multicolumn{6}{|l|}{ Urbana } \\
\hline População analfabeta de 15 anos e mais (\%) & 3,4 & 3,1 & 3,1 & 3,1 & 2,9 \\
\hline Média de anos de estudo - população de 10 anos e mais & 8,8 & 9,3 & 9,3 & 9,6 & 9,7 \\
\hline Assistência escolar - população de 6-9 anos (\%) & 98,6 & 98,4 & 97,3 & 98,7 & 98,7 \\
\hline Assistência escolar - população de 10-14 anos (\%) & 97,8 & 97,7 & 97,1 & 97,5 & 97,7 \\
\hline \multicolumn{6}{|l|}{ Rural } \\
\hline População analfabeta de 15 anos e mais (\%) & 10,5 & 9,2 & 10,8 & 8,9 & 9,4 \\
\hline Média de anos de estudo - população de 10 anos e mais & 6,0 & 6,3 & 6,2 & 6,6 & 6,6 \\
\hline Assistência escolar - população de 6-9 anos (\%) & 95,6 & 96,1 & 98,3 & 98,3 & 97,4 \\
\hline Assistência escolar - população de 10-14 anos (\%) & 91,1 & 93,5 & 94,0 & 95,2 & 94,9 \\
\hline
\end{tabular}

Fonte: DGEEC, 2010-2014

Tabela 8: Satisfação com a democracia no Paraguai (\%)

1995199619971998200020012002200320042005200620072008200920102011

\begin{tabular}{lccccccccccccccccc}
\hline Muito satisfeito & 6 & 7 & 2 & 4 & 1 & 2 & 1 & 0 & 1 & 2 & 1 & 1 & 3 & 4 & 6 & 5 \\
Bastante satisfeito & 22 & 15 & 14 & 20 & 11 & 8 & 5 & 9 & 13 & 15 & 10 & 8 & 19 & 29 & 29 & 34 \\
Não muito satisfeito & 44 & 59 & 40 & 47 & 31 & 28 & 35 & 33 & 44 & 37 & 31 & 39 & 44 & 48 & 40 & 48 \\
Nada satisfeito & 19 & 19 & 42 & 28 & 56 & 58 & 58 & 58 & 41 & 43 & 52 & 48 & 32 & 17 & 23 & 10 \\
\hline
\end{tabular}

Fonte: Latinobarómetro, 2013

Esta limitada capacidade de responder às demandas sociais conflui em um regime deficitário em legitimidade, que se manifesta nos níveis de satisfação com a democracia da população (Tabela 8). Ao analisar dados do Latinobarómetro ${ }^{28}$, percebe-se que a maior parte da população tende a se sentir pouco satisfeita com a democracia, embora também seja possível observar que a valorização geral da mesma tem melhorado desde 2008. A mesma pesquisa revela que $50,2 \%$ dos inquiridos preferem a democracia a qualquer outra forma de governo, 31,5\% apontam que em algumas circunstâncias um governo autoritário pode ser preferível, enquanto que $16,8 \%$ se manifestam indiferentes à questão. Contudo, o Paraguai é o país em que maior quantidade de pessoas entrevistadas prefere um regime autoritário no período 1995-2013, com uma média de 34\%, segundo os dados já citados do Latinobarómetro.

À limitada capacidade de resposta do Estado paraguaio se soma a tradição cultural autoritária sempre presente entre a população paraguaia, que identifica a eficiente resposta a suas necessidades com a gestão de um governo repressor e reforça o desencanto com a democracia como regime político. Os governos da ANR posteriores à queda de Stroessner atuaram para que os 
excessos cometidos ao longo do período ditatorial, em termos de violações aos direitos humanos e utilização arbitrária do poder, continuassem sendo encobertos e justificados discursivamente, ao mesmo tempo em que eram exaltadas as obras de infraestrutura construídas durante os períodos de bonança econômica da ditadura e a percepção de baixa criminalidade predominante naquela época ${ }^{29}$. O ideal de um governo com capacidade de resposta continua estando vinculado de forma idílica à imagem da ANR como instituição fornecedora de serviços sociais, para grande parte da população do país.

\section{Conclusões}

Embora o regime democrático paraguaio tenha apresentado avanços formais desde 1989 para se tornar uma democracia de qualidade, principalmente no que corresponde às dimensões de prestação de contas eleitoral e interinstitucional, a persistência de dificuldades no funcionamento do Estado de Direito e as dimensões de conteúdo e resultados incidiram na valorização essencialmente negativa que a população tem do regime, questionando a própria validade da democracia no país. As persistentes debilidades representam riscos reais para a continuidade democrática no Paraguai, que convive com a idealização do autoritarismo que se mantém entre parte da população.

No seu funcionamento atual, o regime paraguaio apresenta todas as atribuições negativas expostas teoricamente por Morlino (2011), constituindo-se em uma democracia mínima dado que nela predominam as subversões das qualidades das dimensões analisadas. A maior atenção que a classe política paraguaia da transição prestou ao aspecto procedimental da democracia, durante um período histórico em que urgia dar sinais concisos de um afastamento do modelo autoritário stronista em busca do apoio da comunidade internacional, se manifesta na afirmação das regras de jogo eleitorais como mecanismo de nomeação de autoridades, no reconhecimento de direitos políticos da população e na concessão de maiores garantias à liberdade individual, dimensões que aparecem com maiores níveis de qualidade comparativa no caso paraguaio. A vigência previsível destas dimensões na práxis política nacional é a base argumentativa para a definição democrática do regime, ideia perpetuada no discurso político paraguaio que obvia todas aquelas dimensões em que a qualidade ainda é baixa ou nas quais não se conseguiu consolidação, como são a igualdade, o império da lei e a capacidade de resposta governamental, com particular ênfase na necessária luta contra a corrupção.

Atualmente, grande parte da sociedade paraguaia não conta com os recursos materiais nem simbólicos para o pleno exercício da sua cidadania, enquanto sua compreensão deficiente dos processos políticos é perpetuada pela carência de análise e de debate nos meios massivos de comunicação, além da escassez de fontes de informação plurais ou independentes. Percebe-se, também, a necessidade de fortalecer a formação de comunicadores na história recente e conjuntura socioeconômica do país, com o objetivo de que seu trabalho estimule a compreensão pública dos processos políticos, incentivando a participação e contribuindo a erradicar a criminalização do protesto social.

A democracia no Paraguai continuará sendo débil e carente de legitimidade enquanto não se der resposta às necessidades da população mais vulnerável e enquanto esta não se reconhecer como sujeito de direito. Para isso, é necessário promover políticas de bem-estar integrais, que busquem responder às necessidades destes setores e estimulem sua independência econômica, mediante a desprecarização do trabalho e a ampliação e a melhoria da cobertura do serviço de previdência social, com especial atenção à inclusão das mulheres no mercado de trabalho. Ademais, as instituições governamentais devem apontar a melhorar a qualidade da liberdade de forma paralela à qualidade da igualdade: liberdade para a expressão individual sem medo de ser objeto de persecução judicial, liberdade para a definição da vontade política, liberdade para a ação com o objetivo de conseguir maior justiça social.

Só mediante o fortalecimento das dimensões de conteúdo e de resultados, com respostas às necessidades mais urgentes da população, haverá estímulos reais e oportunidades para a participação que sejam coerentes com a já alcançada qualidade das eleições. Enquanto isso não ocorrer, o exercício do sufrágio continuará não sendo um indicador válido do funcionamento da democracia no Paraguai, pois seguirá ligado ao surgimento de incentivos econômicos particulares ou ao clientelismo partidário, correspondentes à exploração das carências da população enquadrada dentro do império da corrupção e da impunidade. A situação de democracia mínima no Paraguai se limita a uma série de procedimentos rotineiros e deficitários em conteúdo democrático, realizados na base de uma competição injusta, em que a incidência efetiva da população não é promovida nem sempre permitida. 


\section{Referências}

ABENTE BRUN, Diego. Estatalidad y calidad de la democracia en Paraguay. América Latina Hoy, v. 60, p. 43-66, 2012. BACHERO, Regina; LEGUIZAMÓN, Corina; FERNÁNDEZ, Raquel. Leyes sin políticas, políticas sin presupuesto, son letra muerta. In: COORDINADORA DE DERECHOS HUMANOS DEL PARAGUAY (CODEHUPY). Derechos humanos en el Paraguay 2014. Asunción: CODEHUPY, 2014.

BARREDA, Mikel; BOU, Marc. La calidad de la democracia paraguaya: un avance sobre caminos tortuosos. América Latina Hoy, v. 56, p. 133-161, 2010.

BENÍTEZ, Francisco; LEGUIZAMÓN, Dante. Impunidad selectiva en las ejecuciones arbitrarias de campesinos y campesinas. In: COORDINADORA DE DERECHOS HUMANOS DEL PARAGUAY (CODEHUPY). Derechos humanos en el Paraguay 2014. Asunción: CODEHUPY, 2014. CAPUTO, Luis. El despojo del tekoha y las encomiendas sexuales. In: COORDINADORA DE DERECHOS HUMANOS DEL PARAGUAY (CODEHUPY). Derechos $h u$ manos en el Paraguay 2012. Asunción: CODEHUPY, 2012. COORDINADORA DE DERECHOS HUMANOS DEL PARAGUAY (CODEHUPY). Derechos humanos en el Paraguay 2009. Asunción: CODEHUPY, 2009.

COMISIÓN DE VERDAD Y JUSTICIA, PARAGUAY (CVJ). Informe final, Tomo IV, Parte I. Asunción: CVJ, 2008.

DAHL, Robert. Polyarchy: participation and opposition. New Haven:Yale University Press, 1971.

DUARTE RECALDE, Liliana Rocío. Límites de la democracia electoral en el Paraguay. In: Proyecto Sociedad Civil Topu'ã Paraguay. Jóvenes Investigadores. Asunción: USAID, 2013a. _. Paraguay: interrupción al proceso de consolidación de la democracia. Revista de Ciencia Política, v. 33, n. 1, p. 303-324, 2013 b. _. Revisión histórica de la instauración del modelo económico agroexportador en Paraguay. Revista Encrucijada Americana, v. 7, n. 1, p. 11-24, 2014.

FOGEL, Ramón. Políticas ambientales. In: ROJAS, Luis (comp.). Gobierno Lugo: herencia, gestión y desafíos. Asunción: BASE-IS, 2009.
GALEANO, Adelaida. Signos de un pasado autoritario que permanecen. In: COORDINADORA DE DERECHOS HUMANOS DEL PARAGUAY (CODEHUPY). Derechos humanos en el Paraguay 2014. Asunción: CODEHUPY, 2014. GAUTO, Enrique. Una Defensoría del Pueblo que nos sigue dejando en indefensión. In: COORDINADORA DE DERECHOS HUMANOS DEL PARAGUAY (CODEHUPY). Derechos humanos en el Paraguay 2014. Asunción: CODEHUPY, 2014.

MARTENS, Juan. El aumento de la poblacion penal refleja el endurecimiento de la política criminal. In: COORDINADORA DE DERECHOS HUMANOS DEL PARAGUAY (CODEHUPY). Derechos humanos en el Paraguay 2014. Asunción: CODEHUPY, 2014.

MARTENS, Juan; ORREGO, Roque. Personas travestis, trabajadoras sexuales y empobrecidas son las principales víctimas. In: COORDINADORA DE DERECHOS HUMANOS DEL PARAGUAY (CODEHUPY). Derechos humanos en el Paraguay 2009. Asunción: CODEHUPY, 2009.

MORLINO, Leonardo. Changes for democracy. Oxford: Oxford University Press, 2011.

O'DONNELL, Guillermo. Delegative democracy. Jorunal of Democracy, v. 5, n. 1, p. 55-69, 1994.

PALAU,Tomás. El desarrollo rural en el Paraguay 2009: Detalles de una deuda anunciada. Diálogos, IPRDS, n. 20, p. 1-3, 2009.

PRZEWORSKI, Adam. Qué esperar de la democracia: límites y posibilidades del autogobierno. Buenos Aires: Editorial Siglo XXI, 2010.

RODRÍGUEZ, José. ¿Cómo se le roba a la Nación? Los mecanismos de la evasión y elusión fiscal más empleados. Asunción: Proyecto Alianza Ciudadana para la Transparencia y el Desarrollo Paraguay, 2012.

UNITED STATES AGENCY FOR INTERNATIONAL DEVELOPMENT (USAID). Paraguay democracy and governance assessment.Vermont: ARD, Inc., 2009.

SCHUSTER, Christian. Clientelismo y el juego político de profesionalizar el empleo público en Paraguay. Documento de Trabajo. Asunción: CADEP, 2013.

\section{Democratic quality in Paraguay: from persisting weaknesses to stalled advances}

\footnotetext{
Abstract:

This paper addresses the current quality of democracy in Paraguay, analyzing the way in which the dimensions concerning procedures, content and results of democracy have developed or stalled in this country since the regime change in 1989 . In this sense, we identify that the electoral and horizontal accountability established throughout the transition period have been the dimensions that have shown the most consistent quality, while equality as a content of democracy and the results dimension show the greatest weaknesses, leading towards the questioning of the very existence of democracy in this country.
}

Key words: Paraguay; quality of democracy; political parties; responsiveness; legitimacy. 


\section{La calidad de la democracia paraguaya: entre debilidades persistentes y avances truncados}

\section{Resumen:}

El presente trabajo revisa la situación actual de la calidad de la democracia paraguaya, analizando la manera en que las distintas dimensiones procedimentales, sustantivas y de resultado se han fortalecido o estancado desde la apertura del régimen en 1989. De esta manera, identificamos que la rendición de cuentas electoral e institucional instauradas desde el proceso de transición han sido las dimensiones que registraron avances más claros en términos de calidad, mientras que la dimensión sustantiva correspondiente a la igualdad y la dimensión de resultados presentan grandes debilidades, sentando las bases para el cuestionamiento de la vigencia del régimen en el país.

Palabras clave: Paraguay; calidad de la democracia; partidos políticos; capacidad de respuesta estatal; legitimidad. 